Research Article

\title{
The Impact of DNA Methylation on IL6 mRNA Levels in Hematinic Deficiency and Atopy-Associated Recurrent Aphthous Stomatitis Patients
}

\author{
Nanan Nur'aeny $\mathbb{D}^{1},{ }^{1}$ Dida Akhmad Gurnida $\mathbb{D}^{\mathbb{D}},{ }^{2}$ Oki Suwarsa $\mathbb{D}^{3},{ }^{3}$ and Irna Sufiawati $\mathbb{D}^{4}$ \\ ${ }^{1}$ Faculty of Medicine, Universitas Padjadjaran, Bandung, Indonesia \\ ${ }^{2}$ Child Health Department, Faculty of Medicine, Universitas Padjadjaran, Bandung, Indonesia \\ ${ }^{3}$ Dermatology and Venereal Disease Department, Faculty of Medicine, Universitas Padjadjaran, Bandung, Indonesia \\ ${ }^{4}$ Oral Medicine Department, Faculty of Dentistry, Universitas Padjadjaran, Bandung, Indonesia \\ Correspondence should be addressed to Nanan Nur’aeny; nanan.nuraeny@fkg.unpad.ac.id
}

Received 23 February 2021; Revised 28 March 2021; Accepted 2 April 2021; Published 12 April 2021

Academic Editor: Amol Gadbail

Copyright (c) 2021 Nanan Nur'aeny et al. This is an open access article distributed under the Creative Commons Attribution License, which permits unrestricted use, distribution, and reproduction in any medium, provided the original work is properly cited.

\begin{abstract}
Objective. To investigate the DNA methylation using pyrosequencing and its effects on the upregulation of IL6 mRNA in patients with recurrent aphthous stomatitis (RAS) in connection with hematinic deficiency and atopy. Material and Methods. This crosssectional study was conducted at Dr. Hasan Sadikin Hospital, Bandung, from January-March 2019 and was approved by the Health Research Ethics Committee of Universitas Padjadjaran (Ethics No. 990/UN6.KEP/EC/2018). Furthermore, the subjects had RAS ulcers with a history of at least twice a year along with atopy and dietary imbalance with no history of recurrent intraoral herpes or any systemic diseases. This study was performed on 23 RAS patients and 21 healthy subjects, and the sampling was carried out consecutively. The blood samples were collected from all the subjects, and then, the DNA and RNA were extracted from the peripheral blood mononuclear cells (PBMCs). Consequently, the bisulfite-modified DNA was used to confirm the methylation status of the IL6 gene promoter through the pyrosequencing method. The methylation levels of the IL6 promoter were assessed by a reverse transcriptase-polymerase chain reaction technique. The gene expression of RAS and the control group was analyzed by the $2^{-\Delta \Delta} C_{\mathrm{T}}$ method. The statistical analysis using the Mann-Whitney $U$ test was conducted to evaluate IL6 mRNA levels and DNA methylation with $p$ value $<0.05$ considered to be statistically significant. Result. The IL6 mRNA levels were approximately 1.88 -fold in RAS patients, and there was a significant relationship between the expression of the IL6 gene and the increased risk of RAS $(p<0.001)$. It was reported that four out of six sites in the cytosine phosphate guanine (CpG) island IL6 promoter had a lower degree of methylation, and two other sites in patients with RAS had greater methylation compared with control, but not statistically significant. Conclusion. This study showed the upregulation of IL6 mRNA levels in RAS patients compared to control. DNA methylation in the present study is at sites 566-658, whereas the location of the IL6 promoter is at sites 1-1684. Thus, it would be necessary conducting some research at other CpG sites of IL6 promoter islands to determine the status of DNA methylation.
\end{abstract}

\section{Introduction}

Recurrent aphthous stomatitis (RAS) is a common oral ulcer discovered by dental professionals worldwide, and the prevalence of RAS varies between populations. Furthermore, the prevalence of RAS was $55 \%$ and $35.6 \%$ discovered in the dental clinic as of 2010-2012 and 2014-2015, respectively
$[1,2]$. Other studies carried out in the midst of the population of 18-year-old adolescents in Brazil discovered to be $24.9 \%$ [3], about $10.84 \%$ RAS were also discovered in Turkey [4], 14\% was reported in the female dental students in King Khalid University Saudi Arabia [5], and 29.38\% was reported in the college students in Beijing University of Chinese Medicine [6]. RAS is considered as a multifactorial process 
of unknown etiology, in which various triggering factors and an immunological disturbance are combined, including genetic $[7,8]$, vitamin B-12, folate, and iron deficiency $[9,10]$ and an allergic condition, such as atopy $[11,12]$ Pain or unpleasant feeling and its recurrency in the oral cavity are always complained by an individual that has RAS, and this condition makes researchers interested in discovering the pathogenesis of RAS and its ultimate goal in finding the appropriate novel therapy [13].

RAS is a chronic oral inflammatory disease with an inflammatory mechanism, and one of the essential modulators that may induce and determine the type of immune response is interleukin 6 (IL6) [14]. The immune system and aberrant cytokine cascade are believed to be critical in the episode of RAS ulcers $[15,16]$. The previous studies on the immunological profiles of the RAS patients showed a significant difference in the distribution of the serum cytokines levels, mainly interleukin-6 (IL6), known as the most potent proinflammatory cytokines in which about $16 \%$ is discovered in RAS and $0 \%$ in control (), and this is shown to be significantly higher in the RAS group than in control [17].

Atopy is the genetic predisposition to develop allergic symptoms triggered by environmental antigens (allergens), potentiated by an underlying aberrant Type 2 inflammatory process $[18,19]$. Atopy is a disease that has an atopic march, ranging from mild to severe symptoms. Individuals with a family history of atopy have a high tendency to experience the aforementioned conditions, such as allergic rhinitis, atopic dermatitis, and even bronchial asthma [20]. The immune response in atopy is characterized by the secretion of IL-4, IL-5, and IL-13. However, IL6 has been shown to promote the differentiation of CD4+ T cells into Th2 cells that produce IL-4. A previous study found that IL6 levels were specifically elevated in asthmatic subjects compared with healthy controls [21]. Some studies showed that higher associations between polymorphism at IL6-174G/C (rs 1800795) and bronchial asthma were observed in atopic patients [22]. Gharagozlou et al. also performed a study and found that the $G$ allele was significantly more frequent at position -174 in IL6 in atopic patients than in the healthy controls [23]. Based on evidence from many studies, IL6 in atopy is one of the main inflammatory mediators which also plays a major role in the recurrence of RAS. A preliminary study also showed a significant difference in IL6 log levels in the atopic and RAS group compared with the control group [24].

The IL6 gene encodes a cytokine that functions in inflammation and the maturation of B cells [25]. The protein is primarily produced at sites of acute and chronic inflammation, where it is secreted into the serum [26]. The role of genetic variability of the IL6 gene (rs1800795) has been examined in RAS [27-29]. RAS is known to have a genetic background, as atopy and both diseases could also be influenced by environmental factors due to some lifestyle factors such as consumption of food with unbalanced nutrition [30-32].

Epigenetics is recognized as one of the most crucial mechanisms in regulating gene function and expression for different cell types [33]. Nutrients and other bioactive food components potentially regulate gene expressions, such as folate and vitamin B-12. Folate is a metabolic cofactor by carrying and chemically activating single carbons for the biosynthesis of purine nucleotides and thymidylate and for the remethylation of homocysteine to methionine, a metabolic network known as folate-mediated one-carbon metabolism. Methionine, in turn, can be adenosylated to form S-adenosylmethionine (SAM), which is a cosubstrate for several cellular methylation reactions. Purines and thymidylate are required for DNA synthesis, and SAM is required for genome methylation [34].

DNA methylation is a form of epigenetic factor that is closely related to macronutrients and micronutrients. Individuals who are malnourished usually also have micronutrient deficiency, including hematinic [35]. An impaired DNA methylation state can be resolved by appropriate dietary intervention [36]. RAS therapy that has been commonly used is multivitamins supplementation, and most people are not familiar with folic acid, iron, or vitamin B-12 for RAS therapy. This present study is the first study to determine whether DNA methylation plays an essential role in the expression of the IL6 gene in individuals who have RAS with a history of atopy and hematinic deficiency (Figure 1).

\section{Materials and Methods}

2.1. Patients and Healthy Control Study Group. The crosssectional study was conducted at Dr. Hasan Sadikin Hospital, Bandung, from January-March 2019, after approval from the Health Research Ethics Committee of Universitas Padjadjaran (Ethics No. 990/UN6.KEP/EC/2018). The target population was subjects having RAS, atopy, and hematinic deficiency. The inclusion criteria include subjects between 18 and 40 years experiencing the recurrence of RAS twice yearly. Having RAS in the active phase, with a history of atopy (atopic dermatitis/bronchial asthma/allergic rhinitis), as well as an imbalanced diet and the hematinic deficiency (iron/vitamin B12/folic acid), is based on the results of the laboratory examination (Folic acid and vitamin B-12 measured by ELISA using Rayto ${ }^{\circledR}$, ferritin, and total IgE measured by CLIA using $\mathrm{XPT}^{\circledR}$.) The exclusion criteria were recurrent intraoral herpes, gastrointestinal disorders, blood, and systemic diseases. The minimal sample size was 20 for each group, which arrived from an unpaired numeric analytic design. The subject recruitment was carried out based on inclusion and exclusion criteria consecutively without blinding.

Informed consent was made prior to the enrollment, and the subject was asked to fill out some questionnaire forms regarding the history of RAS, atopy, and dietary habit with the food frequency questionnaire form. An oral examination was carried out, and two forms were recorded, i.e., the odontogram form and the oral mucosa form.

The subject was prepared for $5 \mathrm{~mL}$ of the blood sample with the venipuncture method by a clinical pathology assistant. Complete blood count and serology (IgE, anti-HSV 1 IgM and IgG, folic acid, vitamin B-12, and ferritin) were performed. Any subjects with positive anti-HSV1 results were excluded. 


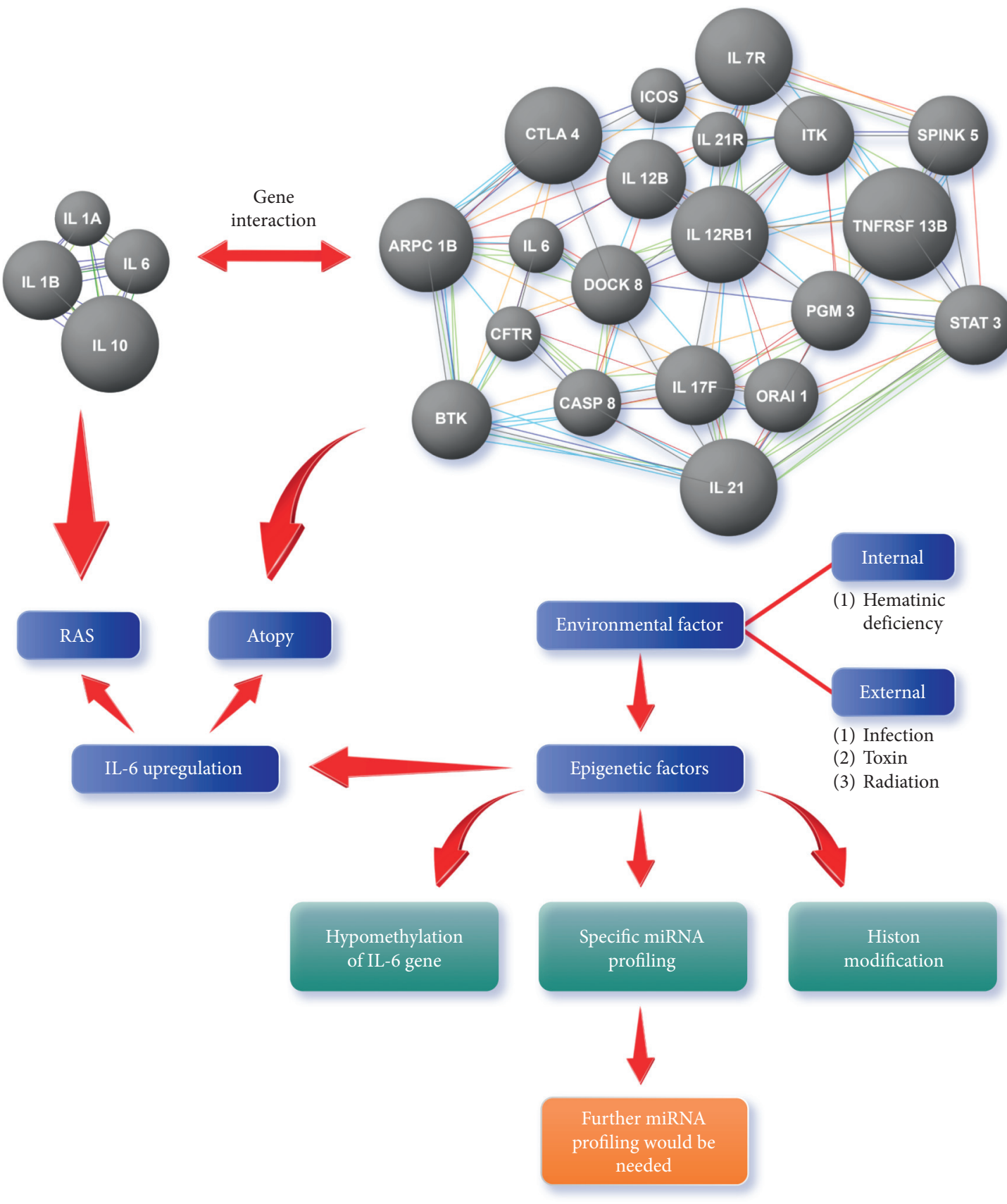

FIGURE 1: Overview of the genomic and epigenomic analysis of the three related conditions: recurrent aphthous stomatitis (RAS), atopy (such as rhinitis allergy, bronchial asthma, and dermatitis atopy), and hematinic deficiency. The grey balls are genes responsible for RAS (left side) and atopy (right side). They interact by coexpression, sharing protein domain, and even direct gene interaction [37]. IL6 is the most important proinflammatory gene affecting RAS and atopy, while its upregulation is interfered with by some external factors (infection, toxin, or radiation), internal factors (folic acid, iron, or B-12 deficiency), as an environmental factor. Also, some epigenetic factors interfere with IL6 gene expression. Strong evidence support hematinic deficiency as a crucial internal environmental factor that affects DNA methylation of some genes. There is no previous study that analyzes the DNA methylation of some important genes in RAS, notably linking with the history of atopy.

2.2. RNA Isolation. Total RNA was extracted from peripheral blood mononuclear cells (PBMCs) according to the Zymo Research ${ }^{\circledR}$ Quick-RNATM MiniPrep Plus kit instructions catalog number R1058. The purity and concentration of the total RNA were estimated by using the Thermo Scientific
Nanodrop $2000{ }^{\circledR}$, and at $260-280 \mathrm{~nm}$, and the purity of RNA was assessed. The total RNA was shown by gel electrophoresis of the individual samples on a $1 \%$ agarose gel [38]. The next step after obtaining the RNA is to perform the reverse transcriptase-polymerase chain reaction (RT PCR) procedure [39]. 
2.3. RT PCR Procedure. The materials used for the RT PCR process were $10 \mu \mathrm{l}$ Sybr sensitivity, primer forward for the IL6 gene ( $5^{\prime}$-GCT TCT GAA CCA GCT TGA CC-3') and primer reverse for the IL6 gene ( $5^{\prime}$-GCC TCA GAC ATC TCC AGT CC- $3^{\prime}$ ), primer forward for gene reference (GADPH) (5'-CCC CAC ACA CAT GCA CTT ACC-3') and primer reverse of GADPH ( $5^{\prime}$-CCT AGT CCC AGG GCT TTG ATT- $\left.3^{\prime}\right), 0.8 \mu \mathrm{l}$ each, $0.1 \mu \mathrm{l}$ reverse transcriptase, $0.2 \mu \mathrm{l}$ ribosafe inhibitor, and $6.1 \mathrm{ul}_{2} \mathrm{O}$. All materials were multiplied according to the number of samples examined [40]. All materials were placed into the Eppendorf tubes in a frozen state. The mixture was placed in an $18 \mu \mathrm{l}$ PCR tube, and then, a 2 ul RNA template was added in such a way that the final volume was $20 \mathrm{ul}$. The next step was to insert the PCR tubes into the RT Gene Rotor $\mathrm{Q}^{\circledR}$ PCR machine for 2.5 hours, which consists of several stages, namely, cDNA synthesis, reverse transcriptase inactivation, denaturation, and annealing. Hold cycles: $42^{\circ} \mathrm{C}, 5$ minutes, hold $2: 95^{\circ} \mathrm{C}$ for 2 minutes, cycling $95^{\circ} \mathrm{C}$ for 10 seconds, and temperature $60^{\circ} \mathrm{C}$ for 30 seconds for 40 times.

2.4. RT PCR Data Analysis. The results and data are presented as cycle threshold $\left(C_{\mathrm{T}}\right)$ and then analyzed with a relative quantification method using the $2^{-\Delta \Delta} C_{\mathrm{T}}$ formula (Livak) [41]. The Delta $C_{\mathrm{T}}\left(\Delta C_{\mathrm{T}}\right)$ RAS group is defined as a subtraction from the $C_{\mathrm{T}}$ IL6 and $C_{\mathrm{T}}$ gene reference (GADPH). The Delta $C_{\mathrm{T}}\left(\Delta C_{\mathrm{T}}\right)$ control group is also calculated using the same formula. Delta Delta $C_{\mathrm{T}}\left(\Delta \Delta C_{\mathrm{T}}\right)$ is defined as subtraction between both of the $\Delta C_{\mathrm{T}}$, and the gene expression achieved from the $\Delta \Delta C_{\mathrm{T}}$ quadrat [41, 42].

\subsection{Preparation of DNA and Bisulfite-Treated Genomic DNA} Samples. The protocol for DNA extraction from leukocytes (peripheral blood mononuclear cells/PBMC) requires tools such as centrifuges, water baths, micropipettes of various sizes $(10,200$, and $1000 \mu \mathrm{l})$, concentrators, and $1.5 \mathrm{ml}$ microtubes, as well as materials including RBC lysis solution $1 \mathrm{x}$, ammonium acetate $5 \mathrm{M}$, cell lysis solution, RNAse $4 \mathrm{mg} /$ $\mathrm{ml}$, isopropanol, 70\% ethanol, and TE buffer $\mathrm{pH}$ 8. The DNA preparations required $300 \mu \mathrm{l}$ blood (whole blood), and $900 \mu \mathrm{l}$ $1 \mathrm{x}$ RBC lysis solution is added into the Eppendorf tube and then shaken several times. The solution is stored for at least 10 minutes at room temperature. After 10 minutes, the solution is placed into a centrifuge with a speed of 13000-16000 RPM for 20 seconds to obtain a leukocyte pellet (PBMC). The supernatant is removed and then repeated until there are no more red blood cells, then mixed until homogeneous by vortex for approximately 20 seconds, and $300 \mathrm{~L}$ of cell lysis solution is added until homogeneous by pipette to lyse the cells. RNAse $1.5 \mu \mathrm{l}$ with a concentration of $5 \mathrm{mg} / \mathrm{ml}$ was added in a tube and incubated in a $37^{\circ} \mathrm{C}$ water bath for at least 15 minutes.

The next step is the addition of a protein solution of precipitation (to precipitate the protein), that is, a $5 \mu \mathrm{l}$ ammonium acetate solution, which is then vortexed until the solution looks like milk and then centrifuged for 3 minutes. The supernatant containing DNA is transferred to a new Eppendorf tube filled with $600 \mu \mathrm{l}$ isopropanol, which is mixed several times until the DNA looks like a white thread. After centrifuging for 1 minute, the DNA will look like a white sediment. The supernatant is removed, and then, about $600 \mu \mathrm{l}$ of $70 \%$ cold alcohol is added. The tube is turned over several times to wash DNA. Similarly, the DNA pellets are obtained after centrifugation for 5 minutes. The alcohol is then discarded, and the tube is allowed to dry by turning it over the tissue until the alcohol evaporates. The pellet was then dissolved with $50 \mu \mathrm{l}$ TE buffer $\mathrm{pH}$ 8. The bisulfiteconverted protocol was carried out using the Zymo EZ DNA Methylation-Gold kit ${ }^{\circledR}$ catalog D5005 [43, 44].

2.6. PCR Procedure. The next step after obtaining DNA preparations is to carry out the PCR procedure, with materials used in the form of Pyromark PCR master mix $12.5 \mu \mathrm{l}$, Coralload concentrate $2.5 \mu \mathrm{l}$, primer forward ( $5^{\prime}$-AGG GAT AAT TTA GTT TAG AGT TTA TTT GT- $\left.3^{\prime}\right) 1 \mu$, primer reverse ( $5^{\prime}$-CTC CCT CTC CCT ATA AAT CTT AAT T- $3^{\prime}$ ) $1 \mu \mathrm{l}$ (Biotin), Q solution $5 \mu \mathrm{l}$, Q solution $5 \mu \mathrm{l}$, ddH2O $1 \mu \mathrm{l}$, and DNA bisulfite $\mu \mathrm{l}$ [43].

2.7. Pyrosequencing. The materials used for processing each sample (on plate 1) are streptavidin sepharose three $\mu \mathrm{l}$, binding buffer $37 \mu \mathrm{l}$, PCR product $15 \mu \mathrm{l}$, and Miliq $25 \mu \mathrm{l}$. Plate 2 for pyrosequencing contained $40 \mathrm{ul}$ annealing buffers, which has been added to the sequencing primer in such a way that the final primary concentration of each hole was $0.3 \mathrm{mM}$. Before entering the Pyromark Q96ID, the plates are first processed at the vacuum workstation, where doublestranded DNA is converted into single-stranded DNA, and the order of the primary sequence is determined. The results from plate 2 of the vacuum workstation are stored in the PyroMark Q96ID for further processing by the pyrosequencing procedure of the $\mathrm{CpG}$ assay to see the percent methylation.

The methylation status of the IL6 gene promoter was confirmed using the pyrosequencing method. The bisulfitemodified DNA was amplified using forward and reverse primers via PCR, allowing the conversion of PCR products into single-stranded DNA as a template suitable for pyrosequencing. All samples were heated to $95^{\circ} \mathrm{C}$ for 5 minutes and then amplified for 45 cycles of $95^{\circ} \mathrm{C} 45$ seconds, $54^{\circ} \mathrm{C} 45$ seconds, and $72^{\circ} \mathrm{C} 45$ seconds, followed by the final extension at $72^{\circ} \mathrm{C}$ for 5 minutes. The quality and lack of PCR product contamination were examined on $2 \%$ agarose gel by staining ethidium bromide. After purifying the PCR product using Sepharose beads on the PyroMark Vacuum Preparation Workstation (Qiagen), pyrosequencing was carried out according to the manufacturer's specifications with sequencing primers ( $5^{\prime}$-ATA AGA TTT AGA TTG TGG GTG T-3) using the PyroMark Q96MD (Qiagen) System. The average methylation index (MI) was calculated from the average percentage of methylation for all observed CpG sites [43].

2.8. Statistical Analysis. The statistical analysis was carried out using SPSS software version 21.0 (SPSS, Chicago, IL, USA). Furthermore, the normal distribution test was 
performed using the Kolmogorov-Smirnov test with Lielliefors correction. The quantitative data of DNA methylation were presented as median and minimum-maximum. The gene expression data obtained were evaluated using relative quantification by the $2^{-\Delta \Delta C}$ T method [41]. Similarly, the differences between mRNA IL6 and DNA methylation between RAS and control groups were evaluated using the Mann-Whitney $U$ test. A $p$ value $<0.05$ was considered a significant difference.

\section{Results}

3.1. Subject Characteristics. The population consists of 81 subjects. Of them, 37 were excluded due to reactive results of HSV-1 infection. There are twenty-three RAS subjects (10 men, 13 women, age range 19-38 years old, mean age $23,5 \pm 4,2$ years), and the control group comprises 21 nonRAS subjects proportionally matched by gender and age ( 6 men, 15 women, age range 20-37 years old, mean age $22,7 \pm 3,8$ years). There was no significant difference in the age between RAS patients and controls $(p>0.05)$. Consequently, it was reported that the hematinic level was a significant difference between the two groups for vitamin B-12 levels $(p=0.001)$ based on the Mann-Whitney test, and the atopic disease was discovered only in the RAS group $(p=0.001)$ (Table 1$)$. The dietary recall was conducted by the food frequency questionnaire (FFQ [45], where the resulted majority (91.3\%) of the subjects consumed eggs and milk daily, while a few of them (8.69\%) had the habit of eating fresh vegetables and fruits).

3.2. Reverse Transcriptase PCR for IL6 Gene. The result and data from RT PCR are presented as cycle threshold $\left(C_{\mathrm{T}}\right)$, and (Figure 2) the $C_{\mathrm{T}}$ is the cycle in which the fluorescence level reaches a specified amount (the threshold). This method $\left(2^{-\Delta \Delta} C_{\mathrm{T}}\right.$ formula) [41] immediately uses the $C_{\mathrm{T}}$ information, and the end result is normalized as a change in the expression of the target gene (IL6) in the target sample (RAS) compared to a shown reference sample (control) to a reference gene (GADPH). The mRNA expression levels of the IL6 gene were 1.88-fold changed in the RAS group, and there was a significant association between the expression of the IL6 gene and elevated risk of RAS $(p<0.001)$ (Table 2).

3.3. Methylation Status and mRNA Expression. The six CpG sites of the IL6 gene in RAS and control groups were evaluated (Figure 3), and the probability of DNA methylation in the RAS group was equal to the control group (Table 3). The pyrosequencing result of the IL6 gene promoter region in an RAS patient (Figure $3(\mathrm{~g})$ ).

\section{Discussion}

The present study is the first study linking DNA methylation on IL6 expression, hematinic factors, and atopy in RAS subjects. Furthermore, it was reported that female subjects experience more RAS, although based on gender, it was not statistically significant between the two groups $(p=0.305)$.
Previous research has shown that females experience RAS more frequently than males $[2,46]$. Women have a higher tendency to seek medical care of their disease or discomfort condition and be stressed higher than men [46]. The mean age in the RAS group was not significantly different from that of the control group ( $p=0.405)$. The age range of the subjects was selected according to epidemiological information showing the most common age of RAS at 20 [47]. Productive age tends to have physical and emotional stress, while it is closely related to increased serum cortisol level [48].

A statistically significant difference was observed in serum vitamin B-12 levels. In addition, the serum levels were reported in about $78 \%$ of the RAS subjects with levels above normal (hypercobalamin), and about 95\% in the control group experience high levels (hypercobalamin). This indicates a functional and qualitative deficiency in vitamin B12, which is related to impaired absorption in the tissues and its effect. Furthermore, supplements or food containing vitamin B-12, such as liver, red meat, eggs, shellfish, or dairy products, potentially lead to hypercobalamine [49]. However, it was reported in RAS subjects according to the food frequency questionnaire that when eggs and milk are consumed almost daily, it can affect the emergence of hypercobalamin conditions, but further investigation is needed to ascertain the exact cause and to be aware of more severe disease.

The ferritin level did not differ between the two groups. This is in concordance with the results of the study conducted by Bao et al., and they also showed no significant difference in the decrease of ferritin and folic acid levels between the RAS and control groups [50]. Furthermore, the folic acid levels were normal in both groups, and the difference was not significant. These results were the same as in previous studies, which reported a minority of patients with deficiencies of folate associated with gastrointestinal disorders such as gastritis, peptic ulceration, and appendectomy, medications, $\mathrm{HbE}$ trait, no systemic diseases, or stress [51].

The IgE levels in the two groups did not differ significantly, possibly because the RAS subjects had no recurrence of the atopic disease episode during the study, or during the atopy therapy, in such a way that it affected the decrease in serum IgE levels. There was more history of atopic dermatitis than other atopic diseases. The IgE examination results were not high. Only six RAS subjects showed IgE $>200 \mathrm{IU} / \mathrm{mL}$. Therefore, the number that can be categorized as atopy is only ten in the RAS group, and other subjects need further investigations. In addition, an increase in the $\operatorname{IgE}$ level in RAS patients was reported based on several previous studies related to a history of allergies in RAS subjects. Another factor was an increase in the number of mast cells in the tissues surrounding the lesion $[51,52]$. The correlation analysis on the results of IgE with IL6 in the RAS group showed statistically significant results $(p=0.011)$ similar to previous studies, which showed that IL6 levels increased in the bronchial asthma group because IL6 can increase mast cell proliferation $[52,53]$.

Many inflammatory mediators, including IL-1, IL-2, IL17, and IL-18, have been investigated in RAS [17, 54, 55]. 
TABLE 1: Characteristics of subjects.

\begin{tabular}{|c|c|c|c|}
\hline \multirow{2}{*}{ Characteristics } & \multicolumn{2}{|c|}{ Group } & \multirow{2}{*}{$p$ value } \\
\hline & RAS $(n=23)$ & Control $(n=21)$ & \\
\hline Gender $^{\#}$ & & & $0.305^{*}$ \\
\hline Male & $10(43.5 \%)$ & $6(28.6 \%)$ & \\
\hline Female & $13(56.5 \%)$ & $15(71.4 \%)$ & \\
\hline Age (year) & $23.5(4.2)$ & $22.7(3.8)$ & $0.405^{* *}$ \\
\hline \multicolumn{4}{|l|}{ Hematinic deficiency\#\# } \\
\hline Vitamin B-12 (pg/mL) & $1435.2(464.6-4387.4)$ & $2150(852.2-3086)$ & $0.001^{* *}$ \\
\hline Ferritin $(\mathrm{ng} / \mathrm{mL})$ & $52.7(3.02-174.97)$ & $45.26(2.53-140.13)$ & $0.597^{* *}$ \\
\hline Folic acid (ng/mL) & $19.4(8.08-40.64)$ & $20.45(6.03-46.84)$ & $0.264^{* *}$ \\
\hline Atopy & & & $0.001^{*}$ \\
\hline Dermatitis atopic (DA) & 8 & 0 & \\
\hline DA and bronchial asthma & 2 & 0 & \\
\hline Nonatopic & 13 & 21 & \\
\hline Total IgE (IU/mL)\#\# & $155.7(2.3-234.8)$ & $167.32(73.7-363.8)$ & $0.540^{* *}$ \\
\hline
\end{tabular}

${ }^{*}$ Chi-square test. ${ }^{* *}$ Mann-Whitney Test. \#Average (standard deviation). \#\#Median (range).

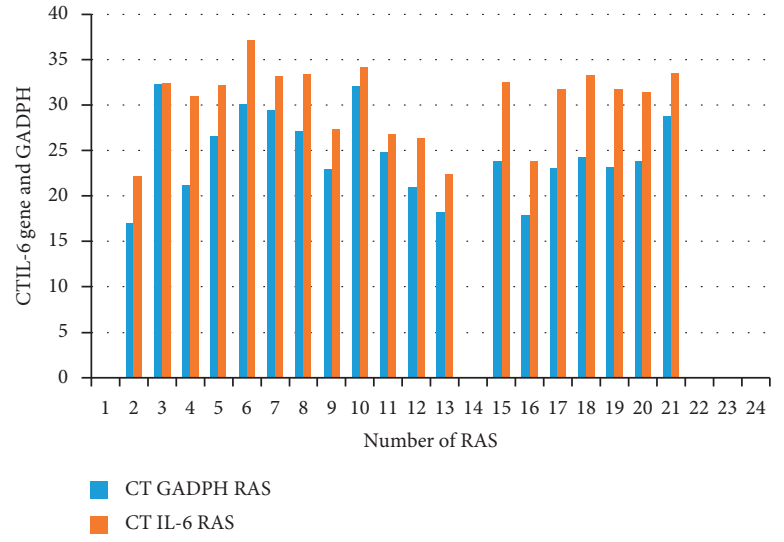

(a)

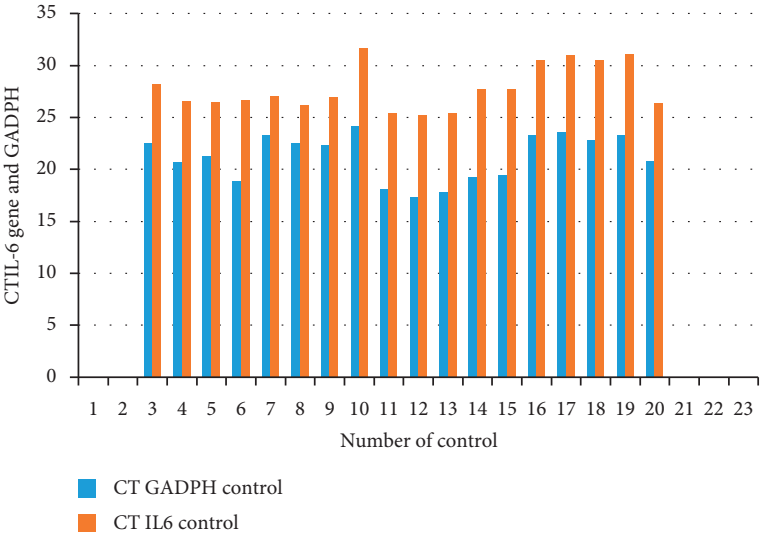

(b)

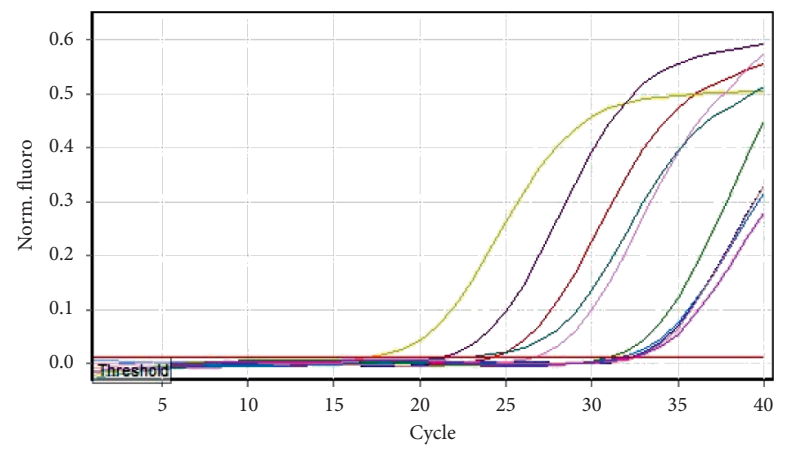

(c)

Figure 2: (a) The cycle threshold $\left(C_{\mathrm{T}}\right)$ of the IL6 gene in the RAS group. (b) The $C_{\mathrm{T}}$ of the IL6 gene in the control group (c) Quantitation data for Cycling A.Green. The result and data from RT PCR are presented as cycle threshold $\left(C_{\mathrm{T}}\right)$, and (Figures $\left.1-3\right)$ the $C_{\mathrm{T}}$ is the cycle in which the fluorescence level reaches a specified amount (the threshold). This method ( $2^{-\Delta \Delta} C_{\mathrm{T}}$ formula) [41] immediately uses the $C_{\mathrm{T}}$ information, and the end result is normalized as a change in the expression of the target gene (IL6) in the target sample (RAS) compared to a shown reference sample (control) to a reference gene (GADPH).

This study investigates IL6 as proinflammatory mediators that play an essential role in RAS and in hematinic deficiency and atopy. Its serum level depends on the expression of the IL6 gene, and its gene expression is influenced by epigenetic factors. One of the epigenetic factors that may be linked to hematinic deficiency and atopy is DNA methylation. The methylation of cytosines in $\mathrm{CpG}$ dinucleotides is an important regulator of gene expression in the human genome.

The study that analyzes DNA methylation on RAS subjects, notably those linking with the expression of 
TABLE 2: Gene expression in the RAS and control group.

\begin{tabular}{|c|c|c|c|}
\hline \multirow{2}{*}{ IL6 gene expression (change fold) } & \multicolumn{2}{|c|}{ Groups } & \multirow{2}{*}{$p$ value } \\
\hline & $\operatorname{RAS}^{* *}(n=23)$ & Control $^{* *}(n=21)$ & \\
\hline Average (SD) & $1.88(0.157)$ & $1(0.343)$ & $<0.011$ \\
\hline
\end{tabular}

${ }^{*}$ Mann-Whitney $U$ test. ${ }^{* *}$ Calculated by the formula of gene expression $=2^{-\Delta \Delta} C_{\mathrm{T}}$ (Livak Method) [41]. SD $=$ standard deviation.

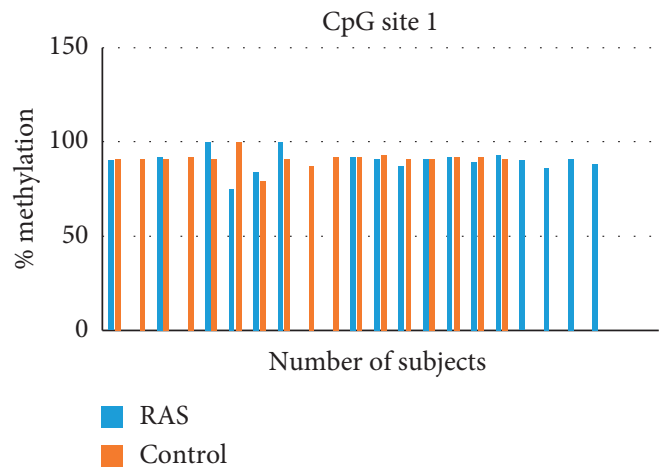

(a)

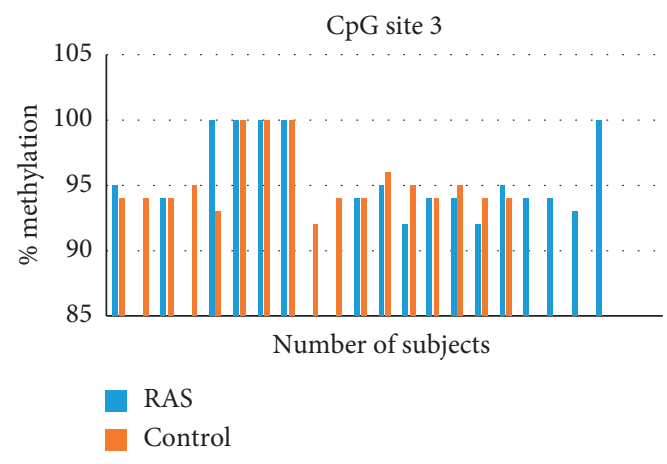

(c)

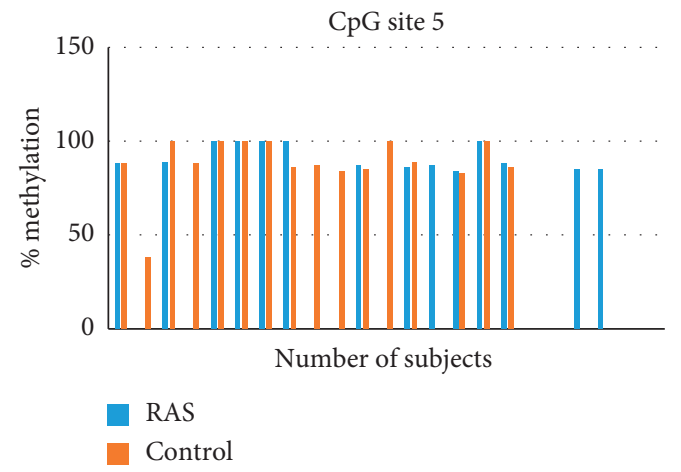

(e)

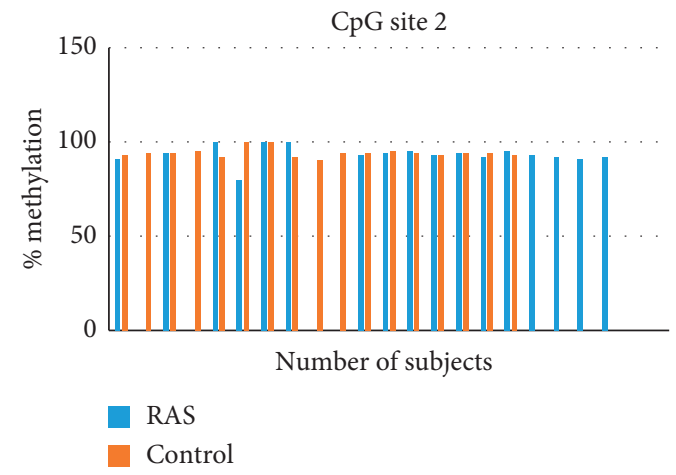

(b)

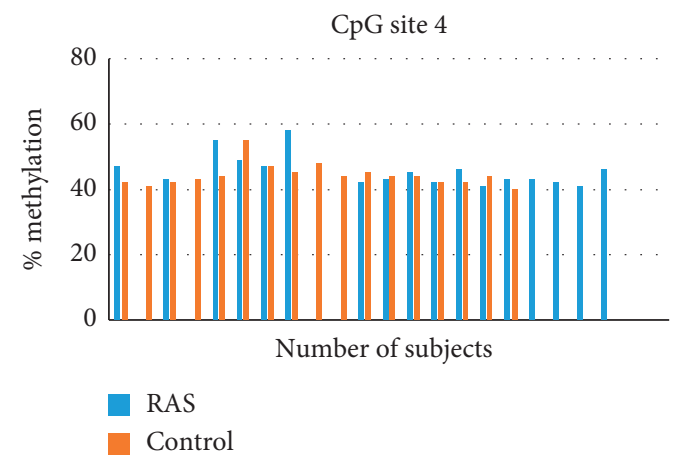

(d)

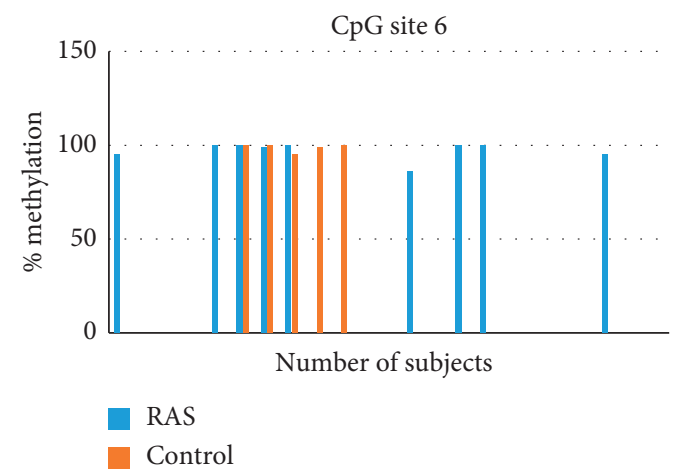

(f)

Figure 3: Continued. 


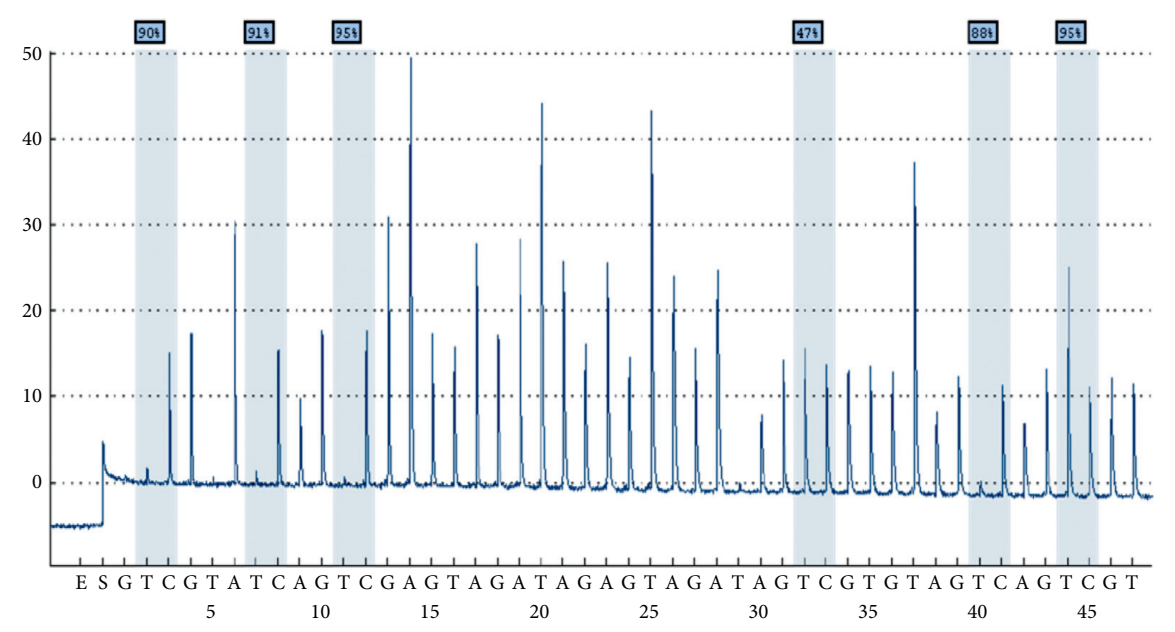

(g)

Figure 3: (a) Percentage of methylation in CpG site 1. (b) Percentage of methylation in CpG site 2. (c) Percentage of methylation in CpG site 3. (d) Percentage of methylation in CpG site 4. (e) Percentage of methylation in CpG site 5. (f) Percentage of methylation in CpG site 6. (g) Pyrosequencing of DNA Methylation in the 6 CpG island IL6 promoter of an RAS patient.

TABLE 3: Methylation DNA in the RAS and control group.

\begin{tabular}{lccc}
\hline DNA methylation (\%) (S) & Groups & Control $^{* *}(n=21)$ & $p$ value* \\
\hline 1. S1 & RAS $^{* *}(n=23)$ & $91(79-100)$ & 0.579 \\
2. S2 & $90(75-100)$ & $94(90-100)$ & 0.580 \\
3. S3 & $93.5(80-100)$ & $95(92-100)$ & 0.838 \\
4. S4 & $95.7(92-100)$ & $44(40-55)$ & 0.578 \\
5. S5 & $43(41-58)$ & $88.4(38-100)$ & 0.822 \\
6. S6 & $91.4(84-100)$ & $99(95-100)$ & 0.797 \\
\hline
\end{tabular}

*Mann-Whitney $U$ test. ${ }^{* *}$ Median (Range), $S=$ site of methylation (CpG site).

proinflammatory genes, has not been performed previously. However, a study conducted by Lu et al. showed the role of one of the epigenetic mechanisms in the upregulation of LncRNA (long noncoding RNA) cancer susceptibility gene 2 (CASC2), IL6, and IL-18 in RAS [56]. This study showed that the percentage of methylation at four CpG site promoter IL6 was lower in the RAS than in the control group. The other two CpG sites indicated were a higher percentage than the control, but it was not statistically significant. The DNA methylation is a methyl group that is covalently added (-CH3) to base $\mathrm{C}$ (cytosine) in the $5^{\prime}-\mathrm{CpG}-3^{\prime}$-dinucleotide. The term $\mathrm{CpG}$ is a base $\mathrm{C}$ connected by a phosphate binds to the base guanine $(\mathrm{G})$ in a DNA sequence [57]. The addition of methyl is carried out by DNA methyltransferase enzymes to genes in regulatory elements such as promoters, which can further suppress gene function (silencing) or trigger gene expression (enhancing) [58].

Subsequently, it was reported that DNA methylation on IL6 gene promoters is believed to increase IL6 expression. The effects of vitamin B-12 and ferritin deficiency reveal the role of nutrients in DNA methylation. Previous studies showed that some food components could change the status of DNA methylation, such as vitamin B as a coenzyme in metabolism "one carbon," methyl-contributing nutrients, micronutrients that can modify "one-carbon" metabolism, and bioactive food compounds that can modify the activity of DNA methyltransferase [59]. The "one carbon" metabolism is an interconnected network of biochemical reactions; a "one-carbon" unit obtained from methylcontributing nutrients is then transferred biochemically and molecularly to DNA synthesis [60]. A vitamin B-12 deficiency can cause hyperhomocysteinemia along with the "methylfolate trap." This can limit the availability of methyl for homocysteine remethylation and DNA methylation [59]. A vitamin B-12 deficiency is associated with a statistically significant hypomethylation according to the studies conducted by Piyathilake et al. [61]. The DNA methylation can be influenced by a deficiency in vitamin B-12 and ferritin or atopic conditions. However, hypomethylation or hypermethylation was not statistically proven. Some gene expressions can be inhibited or enhanced because of hypomethylation or hypermethylation conditions in the $5^{\prime}$ UTR region of the DNA template. This study revealed that IL6 expression was significantly higher in subjects with hematinic deficiency and atopy-related RAS, but its high expression was not related to DNA methylation. This might occur because of other epigenetic factors such as some unique microRNAs (miRNAs) profile. A further study on 
other epigenetic mechanisms of IL6 gene expression in iron, folic acid, vitamin B-12 deficiency, and atopy-related RAS was proposed.

The present study showed that the upregulation of mRNA IL6 was correlated with RAS, hematinic deficiency, and atopy. The upregulation suggests that IL6 gene silencing can be a future novel therapy for RAS, especially in patients with hematinic deficiency and atopy. DNA methylation of CpG islands promoter IL6 in the present study is at sites of 566-658 based on the primer used. Thus, it would be necessary to conduct a further examination at sites 1-565 or 659-1684 at the CpG promoter IL6 location to confirm the status of DNA methylation in RAS. Also, an alternative strategy is needed to lower the IL6 expression by inhibiting the transcription with another epigenetic modality such as noncoding RNA or histone modification.

Subsequently, it was further discovered that IL6 might be a novel target of RAS treatment, especially those related to hematinic deficiency and atopy. The tocilizumab is needed as a direct anti-IL6 agent or silencing the IL6 gene expression through nanoparticle devices, such as the humanized recombinant monoclonal antibody of the $\operatorname{IgG} 1_{k}$ subclass produced using recombinant DNA technology. In addition, environmental factors that contribute to the DNA methylation changes and IL6 upregulation should be reduced as a primary RAS prevention.

\section{Conclusions}

The present study showed that IL6 expression in RAS is mainly influenced by vitamin B-12 deficiency. It is believed that the influence of vitamin B-12 deficiency on IL6 expression is closely related to DNA methylation. However, the upregulation of IL6 mRNA levels was significantly higher in RAS patients. Furthermore, it was suggested that IL6 is an essential proinflammatory in RAS, which might also be influenced by other epigenetic mechanisms. We realized that this study has some limitations in subject recruitment. Therefore, the next proposed study of those linking DNA methylation CpG islands promoter IL6 at sites 1-565 and noncoding RNA with IL6 expression among RAS comorbid with atopy is absolutely essential.

\section{Data Availability}

All the data used to support the finding of this study are included in the manuscript.

\section{Conflicts of Interest}

The authors of this manuscript declare that they have no conflicts of interest.

\section{Acknowledgments}

The author would like to thank for the funds provided by the Academic Leadership Grant from Universitas Padjadjaran, with grant no. 2476/UN6.C/LT/2018. They also thank the Medical Genetic Research Center of Universitas Padjadjaran and Molecular Genetic Laboratory at the Faculty of Medicine Universitas Padjadjaran.

\section{References}

[1] D. Zakiawati, N. Nur'aeny, and R. Setiadhi, "Distribution of oral ulceration cases in oral medicine integrated installation of Universitas padjadjaran dental hospital," Padjadjaran Journal of Dentistry, vol. 32, no. 3, p. 237, 2020.

[2] N. M. Safely, N. Nur'aeny, and W. Hidayat, "Profil lesi stomatitis aftosa rekuren pada pasien di instalasi Ilmu Penyakit Mulut RSGM Unpad periode 2014-2015," Padjadjaran Journal of Dental Researchers and Students, vol. 1, no. 2, p. 110, 2017.

[3] P. Ricardo, M. D. Souza, R. P. Duquia, and H. Larangeira Jr., "Recurrent aphthous stomatitis in 18-year-old adolescentsprevalence and associated factors: a population-based study," Anais Brasileiros de Dermatologia, vol. 92, no. 5, pp. 626-629, 2017.

[4] Y. Bas, H. Yildiz Seckin, G. Kalkan et al., "Investigation of behçet's disease and recurrent aphthous stomatitis frequency: the highest prevalence in Turkey," Balkan Medical Journal, vol. 33, no. 4, pp. 390-395, 2016.

[5] M. Ajmal, L. Ibrahim, N. Mohammed, and H. Al-Qarni, "Prevalence and psychological stress in recurrent aphthous stomatitis among female dental students in Saudi Arabia," Medicine and Pharmacy Reports, vol. 91, no. 2, pp. 216-221, 2018.

[6] Q. Du, S. Ni, Y. Fu, and S. Liu, "Analysis of dietary related factors of recurrent aphthous stomatitis among college students," Evidence-Based Complementary and Alternative, vol. 2018, Article ID 2907812, 2018.

[7] Z. Ślebioda, E. Szponar, and A. Kowalska, "Recurrent aphthous stomatitis: genetic aspects of etiology," Postępy Dermatologii I Alergol, vol. 2, no. 2, pp. 96-102, 2013.

[8] M. Rathee, M. Bhoria, and P. Boora, "Recurrent aphthous stomatitis: an overview," The Internet Journal of Family Practice, vol. 13, no. 1, pp. 1-6, 2014.

[9] N. F. Khan, M. Saeed, S. Chaudhary, and F. Ghafoor, "Haematological parameters and recurrent aphthous stomatitis," Journal of College of Physicians and Surgeons Pakistan, vol. 23, no. 2, pp. 124-127, 2013.

[10] Y.-C. Wu, Y.-H. Wu, Y.-P. Wang, J. Y.-F. Chang, H.-M. Chen, and A. Sun, "Hematinic deficiencies and anemia statuses in recurrent aphthous stomatitis patients with or without atrophic glossitis," Journal of the Formosan Medical Association, vol. 115, no. 12, pp. 1061-1068, 2016.

[11] C. Veller-Fornasa and P. Gallina, "Expression of pathergy in atopics," Acta Dermatoven APA, vol. 15, no. 3, pp. 144-147, 2006.

[12] N. Nur'aeny, E. F. Sari, and E. Sutedja, "Correlation between oral lesion and total serum IgE level in atopic patient," in Proceedings of the 9th International Dental Federation-Indonesia Dental Association Joint Meeting, p. 41, Yogyakarta, Indonesia, April 2013.

[13] T. Maheswaran, A. Yamunadevi, V. Ilayaraja, J. Dineshshankar, T. Yoithapprabhunath, and N. Ganapathy, "Correlation between the menstrual cycle and the onset of recurrent aphthous stomatitis," Journal of Indian Academy of Dental Specialist Researchers, vol. 2, no. 1, pp. 25-26, 2015.

[14] M. Rincon, "Special issue on interleukin-6 (IL-6)," International Journal of Biological Sciences, vol. 8, no. 9, pp. 1225-1226, 2012. 
[15] I. H. Lydie, V. Simona, P. B. Linhartova et al., "Association study of interleukin-1 family, interleukin-6 and its receptor gene polymorphisms in patients with recurrent aphthous stomatitis," Journal of Oral Pathology and Medicine, vol. 46, no. 10, pp. 1030-1035, 2017.

[16] S. Najafi, H. Youse, M. Mohammadzadeh et al., "Association study of interleukin-1 family and interleukin- 6 gene single nucleotide polymorphisms in recurrent aphthous stomatitis," International Journal of Immunogenetics, vol. 42, pp. 428-431, 2015.

[17] M. A. M. Mimura, R. C. Borra, C. H. W. Hirata, and N. de Oliveira Penido, "Immune response of patients with recurrent aphthous stomatitis challenged with a symbiotic," Journal of Oral Pathology \& Medicine, vol. 46, no. 9, pp. 821-828, 2017.

[18] S. V. President, J. Prescott, D. Zangari et al., "The emerging role of the type 2 inflammatory cascade in atopic diseases," The American Journal of Managed Care, vol. 25, pp. 4-8, 2010.

[19] N. A. Gandhi, G. Pirozzi, and N. M. H. Graham, "Commonality of the IL-4/IL-13 pathway in atopic diseases," Expert Review of Clinical Immunology, vol. 13, no. 5, pp. 425-437, 2017.

[20] S. F. Thomsen, "Epidemiology and natural history of atopic diseases," European Clinical Respiratory Journal, vol. 2, no. 1, Article ID 24642, 2015.

[21] M. Rincon, W. A. Neveu, J. L. Allard et al., "Elevation of IL-6 in the allergic asthmatic airway is independent of inflammation but associates with loss of central airway function," Respiratory Research, vol. 11, pp. 1-10, 2010.

[22] E. Babusikova, J. Jurecekova, M. Jesenak, and A. Evinova, "Association of gene polymorphisms in interleukin 6 in infantile bronchial asthma," Archivos de Bronconeumología (English Edition), vol. 53, no. 7, pp. 381-386, 2017.

[23] M. Gharagozlou, E. Farhadi, M. Khaledi et al., "Association between the interleukin 6 genotype at position-174 and atopic dermatitis," Journal of Investigational Allergology and Clinical Immunology, vol. 23, no. 2, pp. 89-93, 2013.

[24] N. Nur'aeny, I. Sufiawati, O. Suwarsa, and D. A. Gurnida, "Serum IL-6 levels of atopic patients with recurrent aphthous stomatitis (RAS)," Padjadjaran Journal of Dentistry, vol. 31, no. 1, pp. 20-24, 2019.

[25] S. Espa, J. Padrón-morales, V. García-solaesa, and M. Isidorogarcía, "Implications of cytokine genes in allergic asthma," Allergologia et immunopathologia Series, vol. 42, no. 6, pp. 603-608, 2014.

[26] S. Naseem, R. Iqbal, and T. Munir, "Role of interleukin-6 in immunity: a review," International Journal Life Sciences, vol. 4, no. 2, pp. 268-274, 2016.

[27] A. L. S. Guimarães, J. d. F. Correia-Silva, A. R. d. Sá et al., "Investigation of functional gene polymorphisms IL-1 $\beta$, IL-6, IL-10 and TNF- $\alpha$ in individuals with recurrent aphthous stomatitis," Archives of Oral Biology, vol. 52, no. 3, pp. 268-272, 2007.

[28] M. R. Bazrafshani, A. H. Hajeer, W. E. R. Ollier, and M. H. Thornhill, "IL-1B and IL-6 gene polymorphisms encode significant risk for the development of recurrent aphthous stomatitis (RAS)," Genes \& Immunity, vol. 3, no. 5, pp. 302-305, 2002.

[29] N. Karakus, S. Yigit, A. Rustemoglu, G. Kalkan, and N. Bozkurt, "Effects of interleukin (IL)-6 gene polymorphisms on recurrent aphthous stomatitis," Archives of Dermatological Research, vol. 306, no. 2, pp. 173-180, 2014.

[30] B. J. Schlosser, M. Pirigyi, and G. W. Mirowski, "Oral manifestations of hematologic and nutritional diseases,"
Otolaryngologic Clinics of North America, vol. 44, no. 1, pp. 183-203, 2011.

[31] N. Chainani-Wu and A. Nayudu, "Resolution of recurrent aphthous ulcers after discontinuation of cow's milk protein intake," The Journal of the American Dental Association, vol. 148, no. 8, pp. 614-617, 2017.

[32] S. Sharma and A. Litonjua, "Asthma, allergy, and responses to methyl donor supplements and nutrients," Journal of Allergy and Clinical Immunology, vol. 133, no. 5, pp. 1246-1254, 2014.

[33] S. Choi, Nutrients Epigenetics, p. 229, CRC Press Taylor\&Francis Group, London, UK, 2009.

[34] P. J. Stover and M. A. Caudill, "Genetic and epigenetic contributions to human nutrition and Health: managing genome-diet interactions," Journal of the American Dietetic Association, vol. 108, no. 9, pp. 1480-1487, 2008.

[35] B. C. M. R. M. K. Y. Patel, "Prevalence of hematinics defi ciency amongst female students and its correction," Indian Journal of Hematology and Blood Transfusion, vol. 23, no. 3, pp. 88-91, 2018.

[36] D. E. G. Kok, R. A. M. Dhonukshe-rutten, C. Lute et al., "The effects of long-term daily folic acid and vitamin B12 supplementation on genome-wide DNA methylation in elderly subjects," Clinical Epigenetics, vol. 7, no. 1, pp. 1-14, 2015.

[37] D. Warde-Farley, S. L. Donaldson, O. Comes et al., "The GeneMANIA prediction server: biological network integration for gene prioritization and predicting gene function," Nucleic Acids Research, vol. 38, no. suppl_2, pp. W214-W220, 20101.

[38] S. Magdeldin, Gel Electrophoresis-Principles and Basics, p. 376, InTech, Rijeka, Croatia, 2012.

[39] J. A. Bridge, "Reverse transcription-polymerase chain reaction molecular testing of cytology specimens: pre-analytic and analytic factors," Cancer Cytopathology, vol. 125, no. 1, pp. 11-19, 2017.

[40] T. Nolan, J. Huggett, and E. Sanchez, "Good practice guide for the application of quantitative PCR (qPCR)," National Measurement System, vol. 50, 2013.

[41] K. J. Livak and T. D. Schmittgen, "Analysis of relative gene expression data using real-time quantitative PCR and the 2- $\Delta \Delta C_{\mathrm{T}}$ method," Methods, vol. 25, no. 4, pp. 402-408, 2001.

[42] X. Rao, X. Huang, Z. Zhou, and X. Lin, "An improvement of the 2(-delta delta $C_{\mathrm{T}}$ ) method for quantitative real-time polymerase chain reaction data analysis," Biostat Bioinforma Biomath, vol. 3, no. 3, pp. 71-85, 2013.

[43] Y. K. Na, H. S. Hong, W. K. Lee, Y. H. Kim, and D. S. Kim, "Increased methylation of interleukin 6 gene is associated with obesity in Korean women," Molecules and Cells, vol. 38, no. 5, pp. 452-456, 2015.

[44] A. Serrano, M. Asnani-kishnani, C. Couturier, and J. Astier, "DNA methylation changes are associated with the programming of white adipose tissue browning features by resveratrol and nicotinamide riboside neonatal supplementations in mice," Nutrients, vol. 12, no. 461, pp. 1-18, 2020.

[45] A. M. Mahmoud and M. M. Ali, "Methyl donor micronutrients that modify DNA methylation and cancer outcome," Nutrients, vol. 11, no. 608, pp. 1-30, 2019.

[46] S. Patil, S. N. Reddy, S. Maheshwari, S. Khandelwal, D. Shruthi, and B. Doni, "Prevalence of recurrent aphthous ulceration in the Indian Population," Journal of Clinical and Experimental Dentistry, vol. 6, no. 1, pp. 36-40, 2014.

[47] Z. Ślebioda and B. Dorocka-Bobkowska, "Systemic and environmental risk factors for recurrent Aphthous stomatitis in a polish cohort of patients," Postep Dermatologii I Alergologii, vol. 36, no. 2, pp. 196-2011, 2019. 
[48] N. Nur'aeny, D. A. Gurnida, O. Suwarsa, and I. Sufiawati, "Serum level of IL-6, reactive oxygen species and cortisol in patients with recurrent aphthous stomatitis related imbalance nutrition intake and atopy," Journal of Mathematical and Fundamental Sciences, vol. 53, no. 3, pp. 286-296, 2020.

[49] E. Andrès, K. Serraj, J. Zhu, and A. J. M. Vermorken, "The pathophysiology of elevated vitamin $\mathrm{b}_{12}$ in clinical practice," QJM, vol. 106, no. 6, pp. 505-515, 2013.

[50] Z. X. Bao, J. Shi, X. W. Yang, and L. X. Liu, "Hematinic deficiencies in patients with recurrent aphthous stomatitis: variations by gender and age," Medicina Oral, Patologia Oral y Cirugia Bucal, vol. 23, no. 2, pp. e161-e167, 2018.

[51] K. Thongprasom, P. Youngnak, and V. Aneksuk, "Hematologic abnormalities in recurrent oral," Southeast Asian Journal of Tropical Medicine and Public Health, vol. 33, no. 4, pp. 872-877, 2002.

[52] A. Desai, M.-Y. Jung, A. Olivera et al., "IL-6 promotes an increase in human mast cell numbers and reactivity through suppression of suppressor of cytokine signaling 3," Journal of Allergy and Clinical Immunology, vol. 137, no. 6, pp. 18631871, 2016.

[53] S. Deo, K. Mistry, A. Kakade, and P. Niphadkar, "Role played by Th2 type cytokines in IgE mediated allergy and asthma," Lung India, vol. 27, no. 2, pp. 66-71, 2010.

[54] S. S. Bhosale, B. S. Rajput, H. Takkar, S. V. Bhagat, R. M. Vagger, and M. I. K Shaikh, "Establishment of role of IL2, IL-10 and IL-12 in patients with recurrent aphthous stomatitis-a clinical study," Journal of Contemporary Dental Practice, vol. 19, no. 10, 2018.

[55] L. Chen, Z. Ke, Z. Zhou, X. Jiang, Y. Zhao, and J. Zhang, "Associations of IL-1, 6, and 10 gene polymorphisms with susceptibility to recurrent aphthous stomatitis: insights from a meta-analysis," Genetic Testing and Molecular Biomarkers, vol. 22, no. 4, pp. 237-245, 2018.

[56] J. Lu, N. Zhang, and C. Wu, "LncRNA CASC 2 is upregulated in aphthous stomatitis and predicts the recurrence," $B M C$ Oral Health, vol. 20, no. 1, p. 12, 2020.

[57] D. H. K. Lim and E. R. Maher, "DNA methylation: a form of epigenetic control of gene expression," The Obstetrician \& Gynaecologist, vol. 12, no. 1, pp. 37-42, 2010.

[58] P. A. Jones, "Functions of DNA methylation: Islands, start sites, gene bodies and beyond," Nature Reviews Genetics, vol. 13, no. 7, pp. 484-492, 2012.

[59] S. Friso3 and S.-W. Choi, "Gene-nutrient interactions and DNA methylation," American Society for Nutrition Science, vol. 132, no. 8 Suppl, pp. 2382-2387, 2002.

[60] P. J. Stover, "One-carbon metabolism-genome interactions in folate-associated pathologies," The Journal of Nutrition, vol. 139, no. 12, pp. 2402-2405, 2009.

[61] G. L. Johanning, D. C. Heimburger, and C. J. Piyathilake, "DNA methylation and diet in cancer," The Journal of $\mathrm{Nu}$ trition, vol. 132, no. 12, pp. 3814S-3818S, 2002. 